\title{
Effective cybersecurity is fundamental to patient safety
}

\author{
The NHS must reduce its vulnerability and build resilience against future cyber attacks
}

\author{
Guy Martin clinical research fellow ${ }^{1}$, James Kinross senior clinical lecturer ${ }^{11}$, Chris Hankin director ${ }^{2}$ \\ ${ }^{1}$ Department of Surgery and Cancer, Imperial College London, London, UK; ${ }^{2}$ Institute for Security Science and Technology, Imperial College London,
}

The global WannaCry ransomware attack has had a disproportionate effect on the UK healthcare sector, highlighting the poor state of cybersecurity in the NHS and the failure to recognise it as a fundamental matter for patient safety.

WannaCry is trojan malware designed to extort money by holding files to ransom. It exploits a known vulnerability in the Windows operating system that was initially identified and patched by Microsoft in March 2017, with a further patch released after the event. ${ }^{12}$ The attack is widely reported to have used system exploits released by the hacker group the Shadow Brokers but originating from the US National Security Agency. Once a computer is infected the malware creates encrypted copies of files before deleting the originals; the only way to retrieve affected data is to pay the bitcoin ransom. Computer systems across more than 150 countries have been infected, and only the fortuitous intervention of a 22 year old researcher who identified and activated a kill switch in the malware has prevented further spread and disruption. ${ }^{23}$

It is not yet clear exactly how many organisations in the NHS have been affected, or to what extent. It's reported that around 50 trusts were directly affected, and some severely so. Many more hospitals pre-emptively shut down computer systems, substantially escalating the effect of the attack. Either way, the outcome was an unprecedented disruption of clinical care that compromised patient safety and caused a potentially dangerous erosion in public trust of electronic health records and the NHS. The fact that we are unable to accurately measure the effect of this attack is a further indictment of the failings in NHS cybersecurity.

One certainty in cybersecurity is that there will be more attacks, and some of those attacks will succeed. So why was the NHS so severely affected, and how can we reduce the likelihood and impact of future attacks? There have been many recent publicised attacks on healthcare organisations around the world, including the Hollywood Presbyterian Medical Center, the Australian Red Cross Blood Service, and two NHS trusts-Lincolnshire and Goole and Barts Health. ${ }^{4-6}$ The health secretary, Jeremy Hunt, was warned last year by the Care Quality Commission and the national data guardian, Fiona
Caldicott, of the cyber risks to the $\mathrm{NHS}^{7}$; these warnings have gone largely unheeded.

\section{Better protection}

Cyber risk has three elements: threat, vulnerability, and impact. Regular and secure backup means lost or encrypted data can be easily replaced, greatly reducing the effect. However, effective mitigation against cyber risk requires long term investment in infrastructure and people. The implicit approach of the UK government and NHS leadership over a long period has been to ignore the chronic risk of cybersecurity. This has resulted in a prolonged time at risk, akin to a ticking time bomb. Many NHS trusts are still using Windows XP, which has not been secure since the government chose not to extend the $£ 5.5 \mathrm{~m}$ (€6.4m; \$7m) support deal with Microsoft in $2015,{ }^{8}$ while around $£ 1$ bn of infrastructure funding that supports IT has been transferred to prop up everyday activities. ${ }^{9}$ Many NHS organisations spend as little as 1-2\% of their annual budget on IT, compared with $4-10 \%$ in other critical sectors, with only a small proportion of that going on security. ${ }^{10}$

Effective cybersecurity also requires good governance. The multistranded response to this latest incident-in which Hunt has remained largely quiet-underlines the extremely fragmented governance of cybersecurity in the NHS. This is a core issue underpinning the recent attack and affects healthcare more profoundly than other critical sectors such as financial services, energy, or central government. Lack of clarity over governance results in the buck being passed from one organisation to another-NHS Digital, National Cyber Security Centre, Department for Health, NHS Trusts—with no clear accountability at a national level for managing what is self evidently a national problem. Merely repeating the mantra that the government has invested $£ 1.9 \mathrm{bn}$ in cybersecurity will not remediate today's problems, or give assurance that the NHS will be better placed to protect itself in future.

The cybersecurity threat to healthcare is an unavoidable new reality. The recent attack, while hugely disruptive, could have been much worse: malware can easily be equipped to erase or alter data, and an attack by a country during a conflict may have an even greater impact. The NHS must reduce its vulnerability and build resilience as a matter of urgency. The digitalisation 
of healthcare is unquestionably the future, but this digital transformation needs a grown-up and credible strategy that considers the risks and the benefits; effective cyber security is a fundamental prerequisite for patient safety. This attack is a wake-up call.

Competing interests: We have read and understood BMJ policy on declaration of interests and have no relevant interests to declare. Provenance and peer review: Commissioned; not externally peer reviewed.

1 Microsoft. Security update for Microsoft Windows SMB server (4013389). 2017. https:// technet.microsoft.com/en-us/library/security/ms17-010.aspx

2 Sanger DE, Chan S, Scott M. Ransomware's aftershocks feared as US warns of complexity. New York Times 2017 May 14.https://www.nytimes.com/2017/05/14/world/ europe/cyberattacks-hack-computers-monday.html?_r=0
3 Malware Tech. How to accidentally stop a global cyber attack. 13 May 2017.https://www. malwaretech.com/2017/05/how-to-accidentally-stop-a-global-cyber-attacks.html

4 KPMG. Health care and cyber security: increasing threats require increased capabilities. 2015. https://assets.kpmg.com/content/dam/kpmg/pdf/2015/09/cyber-health-care-surveykpmg-2015.pdf

5 Evenstad L. NHS trust recovers after cyber attack. Computer Weekly 2016 Nov 3.http:// www.computerweekly.com/news/450402278/NHS-trust-recovers-after-cyber-attack

6 Cyber Security Intelligence. Easy: hackers take down a hospital. 16 Aug 2016.https:// www.cybersecurityintelligence.com/blog/easy-hackers-take-down-a-hospital-1566.html

7 Care Quality Commission, National Data Guardian. Letter to Secretary of State for Health, 6 Jul 2016. https://www.gov.uk/government/uploads/system/uploads/attachment_data/ file/534790/CQC-NDG-data-security-letter.pdf

8 Gibbs S. UK government PCs open to hackers as paid Windows XP support ends. Guardian 2015 May 26. https://www.theguardian.com/technology/2015/may/26/ukgovernment-pcs-open-to-hackers-as-paid-windows-xp-support-ends

9 National Audit Office. Financial sustainability of the NHS. 2016. https://www.nao.org.uk/ wp-content/uploads/2016/11/Financial-Sustainability-of-the-NHS.pdt

10 Mai H. IT in banks: what does it cost? Deutsche Bank Research, 2012. https://www. dbresearch.com/PROD/DBR INTERNET ENPROD/PROD0000000000299039.pd

Published by the BMJ Publishing Group Limited. For permission to use (where not already granted under a licence) please go to http://group.bmj.com/group/rights-licensing/ permissions 